\title{
Addiction, childhood experiences and nurse's role in prevention: a qualitative study
}

Jila Mirlashari, ${ }^{1}$ Jahanfar Jahanbani ${ }^{2}$ and Jamalodin Begjani ${ }^{3}$

${ }^{1}$ School of Nursing and Midwifery, Tehran University of Medical Sciences, Tehran, Islamic Republic of Iran; Postdoctoral fellow, Women's Health Research Institute, Department of OBGYN, University of British Columbia, Canada. ${ }^{2}$ Department of Oral and Maxillofacial Pathology, Faculty of Dentistry, Islamic Azad University Tehran Medical Sciences, Tehran, Islamic Republic of Iran. ${ }^{3}$ School of Nursing and Midwifery, Tehran University of Medical Sciences, Tehran, Islamic Republic of Iran (Correspondence to: Jamalodin Begjani: Jamalbegjani@gmail.com).

\begin{abstract}
Background: Parenting approach and early childhood experiences are thought to be two important factors in the initiation of substance use.

Aims: We aimed to explore the nurse's role in the prevention of childhood addiction.

Methods: In this qualitative study we conducted in-depth interviews with young men and women who were either in treatment for their addiction or were active drug users as well as with family members and nurses. The data analysis followed Strauss and Corbin's constant comparison method.

Results: The data analysis revealed six categories: traumatic events during childhood, inappropriate parenting approach, Lack of knowledge and a tolerant attitude toward drug use, turning a blind eye on the threat of drug use, nurses' poor experience of drug use prevention, and the lack of a clear definition of the nurse's role in prevention of drug use.

Conclusions: Nurses who work with young people and their families have a special opportunity for prevention, early detection and timely intervention for drug dependency.

Keywords: addiction, prevention, childhood, parenting, qualitative study.

Citation: Mirlashari J; Jahanbani J; Begjani J. Addiction, childhood experiences and nurse's role in prevention: a qualitative study. East Mediterr Health J. 2020;26(2):212-2018. https://doi.org/10.26719/2020.26.2.212

Received: 27/05/17; accepted: 14/01/18

Copyright (c) World Health Organization (WHO) 2020. Open Access. Some rights reserved. This work is available under the CC BY-NC-SA 3.0 IGO license (https://creativecommons.org/licenses/by-nc-sa/3.o/igo).
\end{abstract}

\section{Introduction}

Substance abuse and addiction are preventable disorders that interfere with normal healthy functioning, contributing to physical and behavioural health problems, injuries, lost income and productivity, and family dysfunction (1). Drug abuse and dependency pose a major public health threat and continue to endanger the health and socioeconomic fabric of societies around the world $(2,3)$, especially affecting teenagers and young adults (4). The transition period from mid to late adolescence into early adulthood is identified as a high risk period for drug use. Young people's involvement with negative behaviour during this period may become habituated and develop into lifetime patterns (5).

Opium consumption gradually became prevalent in the Islamic Republic of Iran. According to the United Nations Office on Drugs and Crime (UNODC) the country is suffering from the second most severe addiction to opioids, and the highest rate of heroin and opium addiction per head of population in the world: $20 \%$ of the Iranian population aged 15-60 years is involved in drug abuse, and 1 in 17 is a regular user. The annual opium consumption is 450 metric tons UNODC estimates. Other figures indicate that more than 4 million of the 70 million population are addicted to substances, $69.0-94.6 \%$ of whom are dependent on raw opium, and about $83 \%$ of opioid-dependent individuals who sought treatment services in 2009 were addicted to opium (6).
It has been reported that varied etiological reasons may contribute to the initiation and continuation of drug use, including genetic and social factors (7), family relationships and poor parenting practices (8). While substance use generally begins during the adolescent years, there are known biological, psychological, social and environmental factors that contribute to the risk that begin accumulating as early as the prenatal period. This creates opportunities to intervene very early in an individual's life and thereby prevent substance use disorders (and, along with them, a range of other related behavioural problems) long before they would normally manifest themselves (1).

Research into nurse practitioners and alcohol and drug services has suggested that collaborative care involving nurses could lead to better patient access to help and decrease waiting times and longer consultation times. It also suggested that patient satisfaction outcomes are similar when a drug or alcohol intervention is provided by nurse practitioners or physicians (9). Nurses are recognized as key agents in addressing drug use at the individual, family and community levels. They are one of the largest groups of professionals working in drug misuse (10).

It has been suggested that to achieve more effective drug use interventions, it is better to focus on probable reasons and motivational factors underlying drug and alcohol misuse (11). This is one of the compelling reasons as to why the experiences and the point of view of the 
drug users need to be better understood by people who are involved in the planning services for, and in the care of, these patients. Minimal involvement of Iranian nurses in the field of addictions was actually the major concern of the authors in choosing the subject of addiction for the research topic.

This study aimed to explore the role of nurses in prevention of childhood addiction in Tehran. Therefore, we tried to draw attention to the potential contribution that nurses can make in addressing a major public health problem like addiction in countries such as the Islamic Republic of Iran by building on the results of a qualitative inquiry that explored the early childhood experiences of young drug users.

\section{Methods}

\section{Design}

We used a qualitative method to explore the role of nurses in prevention of childhood addiction. Because of their capacity to explore human behaviours, qualitative methods are well-suited to demystifying the facts about drug use with more accurate information that reflects the daily experiences of substance users' lives (12). Face-to-face, semi-structured interviews were held with participants. Interview questions were open-ended to allow participants to thoroughly describe their opinions, perceptions, and experiences on the nurses' involvement in prevention of addiction. The following questions were asked of the nurses and youth respectively: "Have you ever had the experience of providing care for a young adult or youth who were addicted or were suspicious to any type of drug abuse? If yes, what did you do?" "When was the first time that you were exposed to illegal drugs?" "And tell me about the condition and the reaction of people around you?" "Have you ever had the experience of being helped by a health care worker?"

Subject selection in qualitative research is purposeful; participants are selected who can best inform the research questions and enhance understanding of the phenomenon under study (13). As saturation determines the greater part of qualitative sample size (14), we continued the sampling process till new data did not shed any further light on the issue under investigation. We chose participants of different sex, age and socioeconomic and educational background. The participants were recruited purposefully with the help of staff from medical treatment centres and nongovernmental organizations that aim to help addicts. We also used snowball sampling and from public parks where users gathered.

The participants we interviewed were addicted men and women aged 18-35 years. Since addiction is a complex phenomenon which does not happens overnight, they were asked to talk about their childhood experiences, their relationship with their families, when and how they came to know about drugs, their first drug use experience and the conditions and the environment in which the first drug use took place. Participants were also asked to talk about the probable training and preventive health programmes they undertook during their childhood periods regarding drugs and drug use, and they were asked if any nurses or teachers gave them any information on drugs and addiction. Based on the theoretical sampling, the researchers were guided to interview with nurses and participants family members. In the interviews with the nurses they were asked about their experiences on the prevention of the addiction. The interviews lasted between 30 minutes and 150 minutes over 1-2 sessions. They were audio taped and then transcribed. The qualitative data analysis software MAXQDA-10 was used to manage and analyse the data.

In order to get maximum diversity, some interviews had to be conducted in public places like parks where drug users gather.

During the research process from data collection to analysis and reporting of findings, in order to comply with research ethics, an informed consent form was completed by all participants. Participants were asked to agree to the recording of their interviews and the anonymous use of the information. All participants agreed to the anonymous use of information by the research team, therefore any information that would expose the participants was removed. The participants were assured that the information would be kept confidential and audio recordings would be erased after the end of the study and they were informed of their right to withdraw at any time.

\section{Data analysis}

The data analysis followed Strauss and Corbin's constant comparison method (15). Transcribed interviews were coded by the first author in agreement with the co-investigators, and then the codes were hierarchically organized and revised and repeatedly compared across the data to form the main categories until saturation had been reached and no further themes emerged. Concepts were analysed through the frequent, precise and meticulous reading of the transcripts. All possible meanings of the data were considered and meaning labels assigned. High-level concepts were assigned as categories/themes. During the interviews and data analysis, effective contextual factors in the process of the nurses' experiences in the prevention of addiction, e.g. participants' reactions, were taken into consideration.

By reviewing and comparing the categories and subcategories in terms of their features and dimensions, they were reduced to more-abstract categories. Using memos, prolonged engagement with informants and reflexivity on the data and categories which emerged from analysing the contextual factors, we constantly compared the data.

Credibility was enhanced through member checking, validation of emerging themes in subsequent participant interviews and debriefing with expert supervisors. Prolonged engagements with participants, peer checking and maximum variation in sampling were used for validation and credibility of the data. Four interviews 
with family members and 20 interviews with nurses confirmed the emergent themes.

This study was granted ethical approval by the research committee of the School of Nursing and Midwifery of Tehran University of Medical Sciences. Informed consent was obtained from all participants.

\section{Results}

The data were collected between April 2009 and December 2012, through 44 individual in-depth interviews. Twenty interviews were conducted with drug-dependent young people (10 male, 10 female). Fifteen of these participants were in treatment for their opiate addiction and the rest were actively using at the time of the study. Four interviews were conducted with family members of the participants and 20 interviews were conducted with nurses (Table 1).

Our analysis revealed the following themes related to the childhood experiences and parenting style.

Traumatic events during childhood: Traumatic events in early childhood were a shared experience for the majority of participants, and included physical, sexual and emotional abuse, exposure to parental violence in early childhood, and other family problems such as family breakdown and parental addiction.

- I left the house since I hated my stepmother, she used to beat me up, especially when I lost my dad. I had no reason for staying there, I went to the streets without having money. There I saw a young man asking me to go with him and there was the beginning of the story, he introduced me to the drugs. (Participant 3)

- I had so many problems with my family and no-one in the school knew about it. I couldn't study since my mind was occupied with all those problems, my grades were low and my teacher used to make me feel unworthy. (Participant 2)

- I was about 9 years old; my father was a truck driver and consequently rarely at home. My mother was a user, and I couldn't bear seeing her buying the drugs. That is why I thought I should cover up for her and purchase her drug from the drug seller. This was how it all began. (Participant 14)

Inappropriate parenting approach: Subcategories like disconnection between parents and their child, living in 2 different worlds, parents' high expectations for their children and inappropriate punishment were considered under the main category of "inappropriate parenting approach".

- I had everything in my life, but there was a lack of understanding between us; we were well provided for by our parents, but our relationship was not deep, we were living in let's say parallel lives. (Participant 20)

- It was my parents fault; they forced me to hide the truth because they always expected me to stay as their idealized child but not a real one. (Participant 9)

- None of our family members have the habit of using drugs or alcoholic beverages. As parents, we were never thought about probability of addiction among our children. (Participant 23)

- Our children never asked about illegal drugs and we were thinking that exposing them to these issues might raise their curiosity. (Participant 23)

Lack of knowledge and tolerant attitude toward drug use: A tolerant parental attitude toward drug using was frequently mentioned by participants. It was interesting to hear that opium was considered an acceptable painkiller for a range of pain-related symptoms. Perhaps, lack of knowledge along with a tolerant attitude towards drug use made them prone to addiction.

- I had a chronic back pain and my brother recommended me to use opium. He said, "It is safer and less dangerous than the chemical painkillers." He told me only one puff is enough. I really didn't know that it was an addictive drug. That experience made me think that occasional use is OK. (Participant 12)

Turning a blind eye to the threat of drug use: Based on our interviews, none of the participants had experienced any kind of training programmes related to prevention of drug use or addiction in their schools, family or communities; it was like society had turned a blind eye to the threat of drug use among youth.

- They never taught us anything about the hazards of drugs and drug use, I don't know why, but it was like that; our teachers thought no danger would threaten us. (Participant 17)

- We were so engaged with the problems we had in our family, we were on the verge of divorce with my husband, and he was a drug user, so for a long time we neglected our children. (Participant 42)

Nurses and drug use prevention: We also interviewed 20 nurses and took their experiences regarding drug use prevention among youth. The analysis revealed that nurses are not involved in the field of addiction prevention. The result of our analysis of interviews with the nurses also revealed a number of themes:

The first theme was "low experience about drug use prevention." Nurses noted that there was no training programme regarding the prevention of addiction in their curriculum. The second theme was "the lack of a clear definition of nurses' role in prevention of drug use." They explained that nurses were mainly trapped in the hospitals and clinics and their fundamental role was taking care of patients, not informing the youth of the hazards of drugs and the prevention of addiction.

- Concerning drug use prevention among teens, in fact, there is no structured programme for training us in our nursing curriculum. Also, there is no clear definition of the role of nurses in the prevention of drug use among youths. (Participant 38)

- We don't have a school nurse in our country. The school nurse could have a great role in the early recognition and prevention of any deviation among 


\begin{tabular}{|c|c|c|c|c|c|c|c|}
\hline No. & Participant & Age (years) & Sex & Marital status & No. of children & Education level & $\begin{array}{c}\text { Job experience } \\
\text { (years) }\end{array}$ \\
\hline 1 & Young person & 23 & Male & Single & - & High school & - \\
\hline 2 & Young person & 32 & Male & Single & - & PhD student & - \\
\hline 3 & Young person & 18 & Female & Single & - & High school & - \\
\hline 4 & Young person & 21 & Male & Single & - & Middle school & - \\
\hline 5 & Young person & 31 & Female & Married & 1 & High school & - \\
\hline 6 & Young person & 35 & Male & Married & 2 & Primary school & - \\
\hline 7 & Young person & 35 & Female & Divorced & 1 & Middle school & - \\
\hline 8 & Young person & 19 & Male & Single & - & High school & - \\
\hline 9 & Young person & 21 & Female & Divorced & - & High school & - \\
\hline 10 & Young person & 20 & Female & Single & - & High school & - \\
\hline 11 & Young person & 33 & Male & Married & 1 & Bachelor's degree & - \\
\hline 12 & Young person & 26 & Male & Married & - & Primary school & - \\
\hline 13 & Young person & 28 & Male & Married & - & Middle school & - \\
\hline 14 & Young person & 23 & Female & Single & - & High school & - \\
\hline 15 & Young person & 25 & Female & Married & 1 & Primary school & - \\
\hline 16 & Young person & 23 & Male & Single & - & Middle school & - \\
\hline 17 & Young person & 18 & Male & Single & - & High school & - \\
\hline 18 & Young person & 20 & Female & Single & - & Primary school & - \\
\hline 19 & Young person & 31 & Female & Married & 2 & High school & - \\
\hline 20 & Young person & 30 & Female & Married & 1 & Bachelor's degree & - \\
\hline 21 & Nurse & 20 & Female & Single & - & Bachelor's degree & 1 \\
\hline 22 & Nurse & 28 & Female & Single & - & Master’s degree & 4 \\
\hline 23 & Nurse & 43 & Female & Married & 3 & Bachelor's degree & 15 \\
\hline 24 & Nurse & 21 & Female & Single & - & Bachelor's degree & 1 \\
\hline 25 & Nurse & 50 & Male & Married & 2 & Bachelor's degree & 15 \\
\hline 26 & Nurse & 45 & Male & Married & 1 & Bachelor's degree & 15 \\
\hline 27 & Nurse & 36 & Female & Married & 1 & Bachelor's degree & 10 \\
\hline 28 & Nurse & 33 & Female & Single & - & Master's degree & 10 \\
\hline 29 & Nurse & 35 & Female & Married & 1 & Bachelor's degree & 10 \\
\hline 30 & Nurse & 28 & Female & Single & - & Master's degree & 4 \\
\hline 31 & Nurse & 34 & Male & Married & 2 & Bachelor's degree & 10 \\
\hline 32 & Nurse & 24 & Female & Single & - & Bachelor's degree & 2 \\
\hline 33 & Nurse & 26 & Female & Single & - & Bachelor's degree & 3 \\
\hline 34 & Nurse & 42 & Female & Married & 3 & Bachelor's degree & 15 \\
\hline 35 & Nurse & 34 & Female & Divorced & 1 & Bachelor's degree & 10 \\
\hline 36 & Nurse & 29 & Female & Single & - & Master's degree & 15 \\
\hline 37 & Nurse & 26 & Female & Single & - & Bachelor's degree & 2 \\
\hline 38 & Nurse & 22 & Male & Single & - & Bachelor's degree & 1 \\
\hline 39 & Nurse & 29 & Female & Divorced & - & Bachelor's degree & 5 \\
\hline 40 & Nurse & 28 & Female & Single & - & Bachelor's degree & 5 \\
\hline 41 & Mother & 53 & Female & Married & 3 & High school & - \\
\hline 42 & Mother & 55 & Female & Divorced & 4 & Primary school & - \\
\hline 43 & Mother & 60 & Female & Married & 5 & Primary school & - \\
\hline 44 & Father & 63 & Male & Married & 4 & High school & - \\
\hline
\end{tabular}


kids. They can be in a special position for recognizing children who are susceptible to drug use. (Participant 32)

- I have never thought about my role in the prevention of addiction, nobody has told me before that this is one of your roles. (Participant 36)

\section{Discussion}

The period of early childhood has a critical influence on the later life of individuals $(16,17)$. Our study gives an explicit account of early childhood experiences and its influence on the process of developing drug dependency among young Iranian adults, as described by the study participants. Most of our participants talked about traumatic childhood experiences. This finding is in line with the results of other studies that link physical, sexual and emotional abuse, and inter-parental violence to a sense of humiliation, degradation and low self-respect, lack of security and drug use (18-21).

An appropriate nursing assessment involving a child ought to include an extensive assessment of the family and their circumstances. This would provide a significant opportunity to recognize vulnerable children, to identify risk factors and to identify suitable interventions and referral for necessary services. Families are likely to be at ease with nurses functioning in these roles (22).

Nurses have a pivotal role in child protection and prevention of child abuse and neglect. Advanced practice nurses and those who work in primary care and community resource settings can provide health assessments for susceptible families and recognize risk factors for potential child abuse and neglect. The focus of their work should be directed toward the prediction of potential abuse rather than limited to recognizing abuse that has already happened (22).

Parenting dynamics and its influence on children's behaviour also emerged as an important theme in this study. The majority of the participants were from dysfunctional and broken homes. Some studies have found that adolescents living in dysfunctional families are at a greater risk of drug use (19). The primary socialization theory argues that normative and deviant behaviours are mostly shaped and established during the period from infancy to young adulthood (23). Living in dysfunctional families might lead to lower supervision and protection, fewer opportunities for parental involvement with a child's life, and a greater influence of peers (24).

It is reported that the major obstacles to providing support and timely interventions for at-risk families and individuals include a lack of time and skills, short appointments and long waiting lists for consultations. In fact, some families have learnt that problems must be really critical before they seek support. In this regard, community and school nurses should be considered as among the most appropriately placed health care workers to support families with experience of violence and drug and alcohol abuse problems (16). In our study, no school nurses were involved with the student's problems.

Satisfactory growth and development in children can be dramatically improved by the swift resolution of any parenting difficulties (16). It is documented that the physical and mental health needs of children whose parents are active drug users are greater than for those children whose parents are not drug users (25). Some of the reports by the participants of our study concur with the suggestion that their health care needs, along with emotional needs, were not met by their immediate family. Studies confirm that in communities where young people do not receive consistent, suitable health care, school nurses can provide a cost-effective solution to meeting this need, resulting in a positive impact on the health and educational performance of students (26).

The participants in our study mostly received information about drug use from their friends rather than families, school teachers or nurses. While studies suggest that there is a positive effect from having a conversation with children regarding drugs and highlighting the importance of conveying the information they require (27), the findings of a study in the south of Iran confirms that important organizations like the Ministry of Education do not play a role in youth education and teaching how to avoid drug use as effectively as they should (28). If they are given the correct information by their families, teachers or nurses, children will be less likely to rely on misinformation from friends or from those who try to attract them into illicit drug use $(5,27,29)$. Nurses could replace traditional methods of drug use prevention with morally neutral information which is based on scientific facts (30).

It is clear that school and community nurses can provide unique and significant services for children, adolescents and their families; however, in developing countries such as the Islamic Republic of Iran, nurses are mostly placed in hospitals and clinics. Our data analysis guided us to talk with the nurses. The majority of participants blamed health care workers for not having an active role in the prevention of addiction. Therefore, engaging nurses in the field of addiction prevention, training them in this regard, increasing their knowledge and changing their attitude towards their role in addiction prevention were among the findings of this research.

One of the limitations of this study is that it depends on the participants self-reporting. The participants might blame others, especially their families for their problems and addiction. For this reason, we attempted to conduct all interviews in a private context that was appropriate to the conditions of the participants.

\section{Conclusion}

\section{Contribution of nurses}

Our findings highlight the potential contribution that the nursing profession can offer to those children who are at risk of developing substance use problems. In particular, nurses could perform an important role in relation to children and their families in early detection and timely intervention regarding susceptible and high-risk individuals. We suggest that Iranian nurses, and nurses around 
the world, should be more sensitive to the issue of drug dependency and the determinants of drug use by young people, and should improve their knowledge about appropriate prevention strategies.

Although substance use has become a significant public health problem in the Islamic Republic of Iran, Iranian nurses are minimally involved in this important issue and it is appropriate for them to promote their involvement in the prevention and management of drugand alcohol-related problems. We recommend conducting research on the experience of parents of young drug users. Furthermore, conducting research on young people who resist using drugs could also prove valuable.

\section{Implications for nursing and health policy}

To realize this potential, upskilling of the nursing workforce is essential. Inclusion of subjects on substance use disorders in nursing curricula would enable graduates to better deal with this major public health problem. It is also important to create avenues through which nurses can specialize in this field and provide a more holistic and inclusive service.

These significant aims could be addressed through the allocation of more space for this subject in nursing curricula; the consideration of addiction-related professional development courses for nurses who work in schools or are in close contact with children, adolescents, young people, and their families and communities; and the support of nurses interested in specializing in this subject by funding a postgraduate degree.

Funding: We are grateful to Tehran University of Medical Sciences for funding this research (ID: D/250/310).

Competing interests: None declared.

\section{Expériences en matière d'addiction chez l'enfant et rôle du personnel infirmier dans la prévention : étude qualitative}

\section{Résumé}

Contexte: On pense que l'approche parentale et les expériences vécues dans la petite enfance sont deux facteurs majeurs quant à l'initiation de la consommation de drogues.

Objectifs : La présente étude visait à examiner le rôle du personnel infirmier dans la prévention de l'addiction chez l'enfant.

Méthodes : Dans le cadre de cette étude qualitative, nous avons mené des entretiens approfondis avec de jeunes hommes et femmes qui suivaient un traitement pour leur addiction ou qui étaient des consommateurs de drogues actifs, ainsi qu'avec des membres de leurs familles et des infirmiers. La méthode comparative continue de Strauss et Corbin a été suivie pour l'analyse des données obtenues.

Résultats : L'analyse des données a mis en évidence six catégories : les événements traumatiques vécus durant l'enfance, une approche parentale inadaptée, la méconnaissance et une certaine tolérance vis-à-vis de la consommation de drogues, le fait d'ignorer la menace que représente la consommation de drogues, le manque d'expérience du personnel infirmier en matière de prévention de la consommation de drogues et l'absence de définition claire quant au rôle des infirmiers dans la prévention de la consommation de drogues.

Conclusions : Les personnels infirmiers qui travaillent auprès des jeunes et de leurs familles ont un potentiel particulier en matière de prévention, de détection précoce et d'intervention rapide pour lutter contre la dépendance aux drogues.

$$
\begin{aligned}
& \text { الإدمان: تجارب الطفولة ودور الممرضات في الوقاية: دراسة كيفية } \\
& \text { جيلا ميرلاشاري، جهانفر جهانباني، جمال الدين بكجانى } \\
& \text { الخلاصة } \\
& \text { الخلفية: يُعتقد أن النهج الأبوي وتجارب الطفولة المبكرة من أهم العو امل التي قد تُسهم في بدء تعاطي المخدرات. }
\end{aligned}
$$

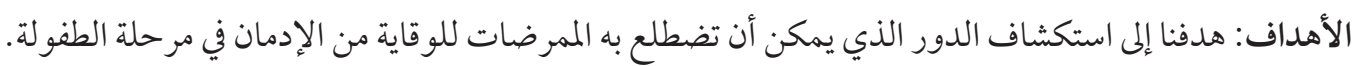

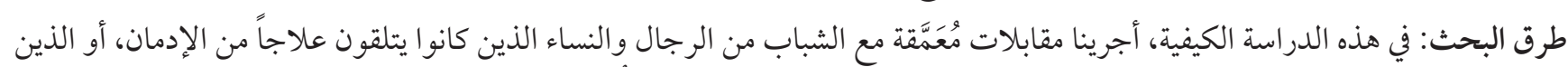

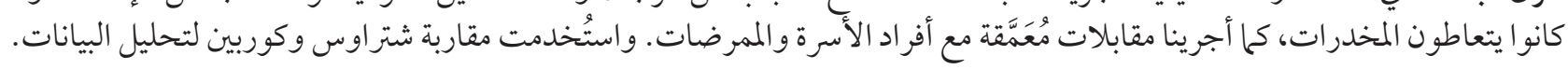

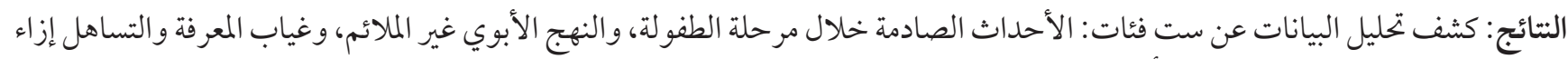

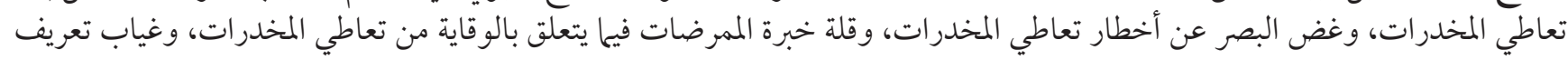

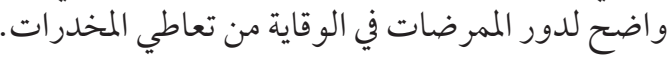

$$
\begin{aligned}
& \text { الاستنتاجات: لدى الممر ضات التي تعمل مع الشباب والأسر فرصة خاصة لتحقيق الوقاية، والكشف المبكر والتدخل في الوقت المناسب بخصوص } \\
& \text { إدمان المخدرات. }
\end{aligned}
$$




\section{References}

1. National Institute on Drug Abuse. Principles of substance abuse prevention for early childhood: a research-based guide. National Institutes of Health; US Department of Health and Human Services: 2016.

2. Rassool GH, Rawaf S. Predictors of educational outcomes of undergraduate nursing students in alcohol and drug education. Nurse Educ Today. 2008;28(6):691-701. PMID:18166248

3. Mirlashari J, Demirkol A, Salsali M, Rafiey H, Jahanbani J. Society and its influences on drug use among young individuals in Tehran, Iran. J Addict Nurs. 2013;24(2):116-21. PMID:24621490; doi:10.1097/JAN.ob013e31826f6846

4. Bryant J. Developing a substance abuse prevention program for parents and youth [thesis]. Madison New Jersey: Drew University; 2008.

5. Miller-Day M. Talking to youth about drugs: what do late adolescents say about parental strategies? Family Relations. 2008;57(1):112 .

6. Zarghami M. Iranian common attitude toward opium consumption. Iranian J Psychiatry Behav Sci. 2015;9(2). PMID:26288642

7. Haber PS, Demirkol A, Lange K, Murnion B. Management of injecting drug users admitted to hospital. Lancet. 2009;374(9697):128493. doi:10.1016/So140-6736(09)61036-9.

8. Sanders MR. Community-based parenting and family support interventions and the prevention of drug abuse. Addict Behav. 2000;25(6):929-42. PMID:11125780

9. $\quad$ Ling S. Nurse practitioners in drug and alcohol: where are they? Australian J Adv Nurs. 2009;26(4):64.

10. Clancy C, Oyefeso A, Ghodse H. Role development and career stages in addiction nursing: an exploratory study. J Adv Nurs. 2007;57(2):161-71. PMID:17214752; doi:10.1111/j.1365-2648.2006.04088.x

11. Mushquash CJ, Comeau N, Stewart SH. An alcohol abuse early intervention approach with Mi'kmaq adolescents. First Peoples Child \& Family Rev. 2007;3(2):17-26.

12. Neale J, Allen D, Coombes L. Qualitative research methods within the addictions. Addiction. 2005;100(11):1584-93. PMID:16277621

13. Creswell JW. Research design: qualitative, quantitative, and mixed methods approaches. Thousand Oaks: SAGE Publications; 2009.

14. Mason M. Sample size and saturation in PhD studies using qualitative interviews. Forum: Qual Soc Res Sozialforschung. 2010;11(3). doi:http://dx.doi.org/10.17169/fqs-11.3.1428

15. Corbin J, Strauss A. Basics of qualitative research: techniques and procedures for developing grounded theory. Thousand Oaks: Sage; 2008.

16. Häggman-Laitila A. Early support needs of Finnish families with small children. J Adv Nurs. 2003;41(6):595-606. PMID:12622868

17. Mirlashari J, Demirkol A, Salsali M, Rafiey H, Jahanbani J. Early childhood experiences, parenting and the process of drug dependency among young people in Tehran, Iran. Drug Alcohol Rev. 2012;31(4):461-8. doi: 10.1111/j.1465-3362.2011.00384.X

18. Magor-Blatch L. Child deaths and statutory services: families and substance use: building a resource for recovery. Communities, Children and Families Australia. 2007;3(1):33.

19. Pournaghash-Tehrani S, Feizabadi Z. Predictability of physical and psychological violence by early adverse childhood experiences. J Family Violence. 2009;24(6):417-22.

20. Kelley ML, Klostermann K, Doane AN, Mignone T, Lam WK, Fals-Stewart W, et al. The case for examining and treating the combined effects of parental drug use and interparental violence on children in their homes. Aggress Violent Behav. 2010;15(1):76-82. PMID:20161505

21. Shin SH, Hong HG, Hazen AL. Childhood sexual abuse and adolescent substance use: A latent class analysis. Drug Alcohol Depend. 2010;109(1):226-35. doi:10.1016/j.drugalcdep.2010.01.013

22. Adams BL. Assessment of child abuse risk factors by advanced practice nurses. Pediatr Nurs. 2004;31(6):498-502. PMID:16411545

23. Cubbins LA, Klepinger DH. Childhood family, ethnicity, and drug use over the life course. J Marriage Fam. 2007;69(3):810-30.

24. Eitle $\mathrm{D}$. The moderating effects of peer substance use on the family structure-adolescent substance use association: quantity versus quality of parenting. Addict Behav. 2005;30(5):963-80. doi:10.1016/j.addbeh.2004.09.015

25. Gance-Cleveland B, Mays MZ. School-based support groups for adolescents with a substance-abusing parent. J Am Psychiatr Nurses Assoc. 2008;14(4):297-309. PMID:21665773

26. Fritsch K, Heckert KA. Working together: health promoting schools and school nurses. Asian Nurs Res. 2007;1(3):147-52. PMID:25030882

27. Kennett J. Talking to your kids. Meanjin. 2002;61(2):34-41.

28. Nakhaee N, Jadidi N. Why do some teens turn to drugs? A focus group study of drug users' experiences. J Addicts Nurs. 2009;20(4):203-8. doi:10.3109/10884600903291158

29. Laoniramai P, Laosee OC, Somrongthong R, Wongchalee S, Sitthi-Amorn C. Factors affecting the experiences of drug use by adolescents in a Bangkok slum. Southeast Asian J Trop Med Public Health. 2005 Jul;36(4):1014-9. PMID:16295561

30. Guzys D, Kendall S. Advocating for a harm-minimization approach to drug education in Australian schools. J Sch Nurs. 2006;22(5):259-63. PMID:17172197 